\title{
Fatty airways: implications for obstructive disease
}

\author{
John G. Elliot ${ }^{1,2}$, Graham M. Donovan $\mathbb{1}^{3}$, Kimberley C.W. Wang (1) ${ }^{2,4}$, \\ Francis H.Y. Green ${ }^{5}$, Alan L. James ${ }^{1,6}$ and Peter B. Noble (10) ${ }^{2}$
}

Affiliations: ${ }^{1}$ West Australian Sleep Disorders Research Institute, Dept of Pulmonary Physiology and Sleep Medicine, Sir Charles Gairdner Hospital, Nedlands, Australia. ${ }^{2}$ School of Human Sciences, The University of Western Australia, Crawley, Australia. ${ }^{3}$ Dept of Mathematics, University of Auckland, Auckland, New Zealand. ${ }^{4}$ Telethon Kids Institute, University of Western Australia, Nedlands, Australia. ${ }^{5}$ Dept of Pathology and Laboratory Medicine, University of Calgary, Calgary, AB, Canada. ${ }^{6}$ School of Medicine and Pharmacology, The University of Western Australia, Nedlands, Australia.

Correspondence: John G. Elliot, West Australian Sleep Disorders Research Institute, Dept of Pulmonary Physiology and Sleep Medicine, Sir Charles Gairdner Hospital, Queen Elizabeth II Medical Centre, Hospital Avenue, Nedlands, Western Australia 6009, Australia. E-mail: john.elliotahealth.wa.gov.au

@ERSpublications

In individuals with elevated BMI, adipose tissue accumulates within the airway wall, correlates with greater wall thickness and airway inflammation and represents a new mechanism for airway pathophysiology in obese asthmatic patients http://bit.ly/2maDoSp

Cite this article as: Elliot JG, Donovan GM, Wang KCW, et al. Fatty airways: implications for obstructive disease. Eur Respir J 2019; 54: 1900857 [https://doi.org/10.1183/13993003.00857-2019].

ABSTRACT Epidemiological studies report that overweight or obese asthmatic subjects have more severe disease than those of a healthy weight. We postulated that accumulation of adipose tissue within the airway wall may occur in overweight patients and contribute to airway pathology. Our aim was to determine the relationship between adipose tissue within the airway wall and body mass index (BMI) in individuals with and without asthma.

Transverse airway sections were sampled in a stratified manner from post mortem lungs of control subjects $(n=15)$ and cases of nonfatal $(n=21)$ and fatal $(n=16)$ asthma. The relationship between airway adipose tissue, remodelling and inflammation was assessed. The areas of the airway wall and adipose tissue were estimated by point count and expressed as area per $\mathrm{mm}$ of basement membrane perimeter (Pbm). The number of eosinophils and neutrophils were expressed as area densities.

BMI ranged from 15 to $45 \mathrm{~kg} \cdot \mathrm{m}^{-2}$ and was greater in nonfatal asthma cases $(\mathrm{p}<0.05)$. Adipose tissue was identified in the outer wall of large airways $(\mathrm{Pbm}>6 \mathrm{~mm})$, but was rarely seen in small airways $(\mathrm{Pbm}$ $<6 \mathrm{~mm}$ ). Adipose tissue area correlated positively with eosinophils and neutrophils in fatal asthma $(\mathrm{Pbm}>12 \mathrm{~mm}, \mathrm{p}<0.01)$, and with neutrophils in control subjects $(\mathrm{Pbm}>6 \mathrm{~mm}, \mathrm{p}=0.04)$.

These data show that adipose tissue is present within the airway wall and is related to BMI, wall thickness and the number of inflammatory cells. Therefore, the accumulation of airway adipose tissue in overweight individuals may contribute to airway pathophysiology. 


\section{Introduction}

Obesity is recognised as an emerging health problem that is not just confined to high-income countries [1]. It is predicted that by 2025 global obesity frequency will reach $18 \%$ in males and $21 \%$ in females [2]. A link between obesity and diseases of various biological systems is well established [3], and includes abnormal respiratory function, particularly asthma. Epidemiological data have shown a positive association between adiposity and asthma and increased asthma severity $[4,5]$. In the United States the majority of patients with severe asthma are obese [6].

The mechanism(s) underlying the association between obesity and asthma has yet to be established. An endocrine role of adipose tissue may contribute to the release of inflammatory mediators in asthma [7]. Alternatively, a direct effect of fat accumulation on the chest and abdomen may reduce lung volume [8], and in turn, airway inflation, leading to increased airway resistance. Such inflammatory and mechanical changes explain, at least in part, the occurrence of an obesity phenotype in cluster analysis of patients with asthma and asthma symptoms $[9,10]$.

We now propose an additional mechanism that abnormal respiratory function in obesity relates to accumulation of adipose tissue within the airways. Increased thickness of the airway wall, referred to as "airway remodelling", is a cardinal feature of asthma that is due to increased thickness of the airway smooth muscle (ASM), oedema and fibrosis [11-13]. Accumulation of adipose tissue may further contribute to increased airway wall thickness and onset of airflow limitation. Geometric effects of wall thickening have been demonstrated in mathematical models: inward wall movement, which obstructs lumen cross-sectional area, and outward wall movement, which uncouples the airway from lung forces that normally favour expansion of the airway lumen $[14,15]$; both increase airway resistance.

To the best of our knowledge, this is the first quantitative estimation of adipose tissue within the airways of human subjects with and without asthma. The present study related adipose tissue area to body mass index (BMI), airway wall thickness and inflammation. Some of the results of this study have been reported previously in the form of an abstract [16].

\section{Methods}

\section{Subjects}

Subjects were post mortem cases included in the Prairie Provinces Asthma Study [17, 18]. Cases were defined as subjects where the cause of death was asthma (fatal asthma), nonrespiratory subjects with a history of asthma (nonfatal asthma), and nonrespiratory without a history of respiratory disease (control). After death, the study team contacted the next-of-kin to obtain consent for autopsy. The next-of-kin were asked to complete a questionnaire which sought information on asthma severity, age of onset, duration of asthma, asthma medications and smoking history. In addition, medication history was obtained (with permission) from the asthma subject's healthcare provider and then assigned a category for asthma severity [19]. This study received ethical approval from the University of Calgary, University of Edmonton, University of Saskatchewan and University of Manitoba [17, 18].

\section{Tissue sampling}

Left lungs were taken at the post mortem examination and fixed by inflation via the blood vessels and airways with isotonic glutaraldehyde fixative $(2.5 \%$ in $0.1 \mathrm{M}$ phosphate buffer, $\mathrm{pH} 7.3)$ at a pressure of $20 \mathrm{cmH}_{2} \mathrm{O}$. A stratified sampling technique was applied as described previously [20]. This sampling procedure was developed to ensure that similar anatomical levels (generations) of airways were sampled, regardless of lung size. Tissue blocks were embedded in paraffin wax, sectioned at $5 \mu \mathrm{m}$, mounted on glass slides and stained with haematoxylin and eosin (H\&E).

\section{Morphometry}

On airways cut in cross-section, the perimeter of the airway basement membrane $(\mathrm{Pbm})$ was determined by counting intersections of the $\mathrm{Pbm}$ with a square-lattice grid of known dimensions using a Zeiss AxioPlan light microscope (Oberkochen, Germany). At a known magnification, a grid was placed at random over a cross-section of airway and the number of intersections between the grid lines and the luminal aspect of the epithelial basement membrane were counted and the perimeter then calculated [21]. Airway wall dimensions including total airway wall area and the area of adipose tissue were measured using point counts on small $(\mathrm{Pbm}<6 \mathrm{~mm})$, medium $(\mathrm{Pbm} 6-12 \mathrm{~mm})$ and large $(\mathrm{Pbm}>12 \mathrm{~mm})$ airways. The outer boundary of the airway was determined by the border between the airway wall and the surrounding lung parenchyma for membranous bronchi/bronchioles. For cartilaginous airways, the outer boundary was set by an imaginary line connecting the outer perichondrium of the cartilage plates and excluded the adventitia (figure 1a). Adipose tissue was defined as clusters of cells containing a large lipid 

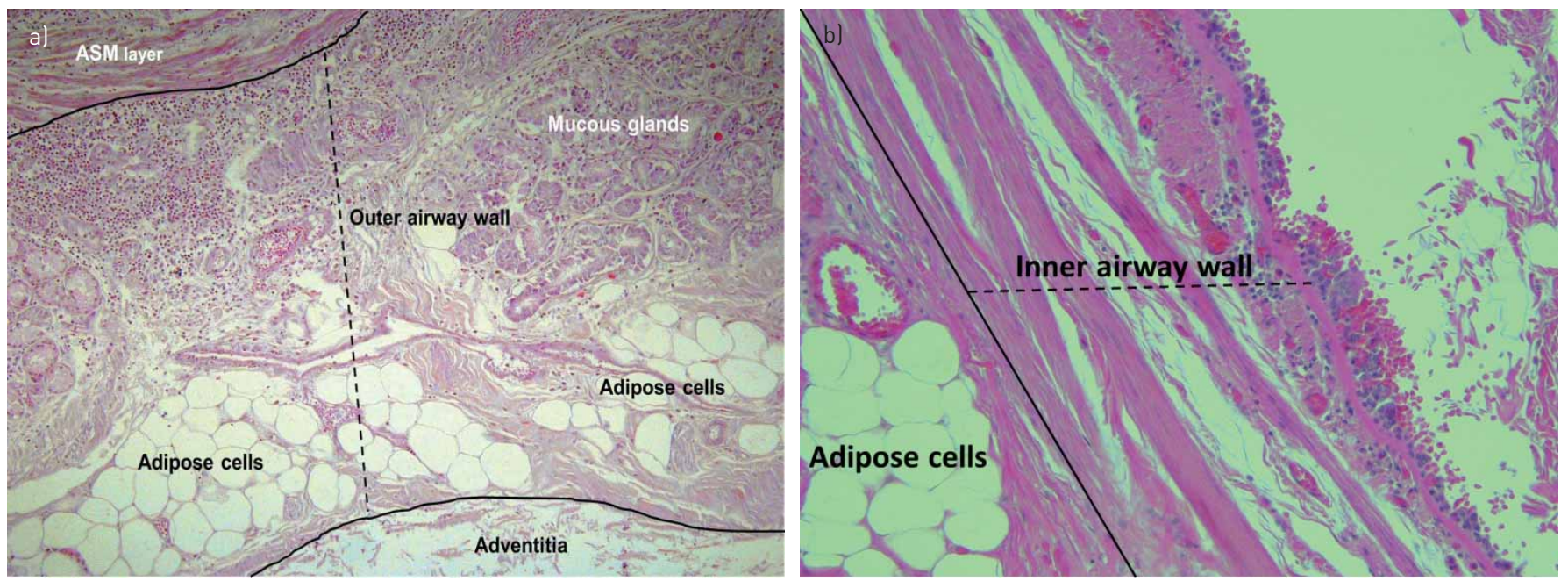

FIGURE 1 Micrographs $(\times 200)$ of a) the outer airway wall, between the airway smooth muscle (ASM) layer and the airway adventitia showing adipose tissue and mucous glands and b) the inner airway wall (submucosa), between the basement membrane and ASM layer in a case of fatal asthma stained with haematoxylin and eosin. Inflammatory cells were counted within the inner airway wall.

droplet, surrounded by a scant cytoplasm and flattened noncentrally located nuclei. During preparation of the tissue the lipid droplet is dissolved and the cell appears empty and has a signet ring appearance.

In a subgroup of cases (12 control, 13 nonfatal asthma and 13 fatal asthma) where the same airways could be positively identified from archived tissue blocks, the number of eosinophils and neutrophils within the submucosa were counted on $5-\mu \mathrm{m}$ sections stained with $\mathrm{H} \& \mathrm{E}$, based on a staining and morphology criteria [22]. Cell counts were made within the inner airway wall, defined as being between the basement membrane and the outside of the ASM layer (figure 1b) [22].

\section{Data analysis}

Comparisons were undertaken using statistical software SigmaPlot (version 13.0; Systat Software, Chicago, IL, USA) and graphical analysis by Prism (version 8.1.2; GraphPad Software, San Diego, CA, USA). Summary statistics, including mean \pm SD for normally distributed variables, median (interquartile range) for non-normally distributed variables and counts and percentages for categorical variables were calculated. Subjects were grouped by demographic characteristics, asthma history and asthma severity and groups were compared using t-tests or Chi-squared tests, as appropriate. Separate analysis for airway size groups were undertaken using ANOVA and post hoc tests, as appropriate. Eosinophil and neutrophil area densities were log-transformed prior to analysis. The relationship between adipose tissue area within the airway wall and other variables were tested using Pearson's correlation and multiple linear regression models.

\section{Results}

Airways were examined from 15 control subjects, 21 nonfatal asthma and 16 fatal asthma cases where weight and height data were available. BMI ranged from 15 to $45 \mathrm{~kg} \cdot \mathrm{m}^{-2}$ across groups and was significantly increased in the nonfatal asthma cases compared with control subjects and fatal asthma cases $(\mathrm{p}<0.05)$. Corticosteroid use (oral and/or inhaled) was increased in the fatal asthma cases $(92 \%)$ compared with nonfatal asthma cases $(53 \%, \mathrm{p}=0.04)$. There were no other differences in subject characteristics between the groups (table 1).

1373 airways were examined with a mean of $26 \pm 1.4$ airways per case. Airways were well matched for size (table 2); however, in airways grouped as $>6 \mathrm{~mm}$, the $\mathrm{Pbm}$ was modestly greater $(\mathrm{p}<0.05)$ in fatal asthma $(16.12 \pm 1.49 \mathrm{~mm})$ compared with nonfatal asthma $(14.66 \pm 1.89 \mathrm{~mm})$. While adipose tissue was identified in airways from all subject groups, it was limited to the outer airway wall (figure 1) and was observed predominantly in large- to medium-sized airways $(>6 \mathrm{~mm} \mathrm{Pbm})$. Adipose tissue was seldom observed in the small airways $(<6 \mathrm{~mm} \mathrm{Pbm})$. No differences were seen in the amount of adipose tissue between the anterior or posterior bronchus of the left lower lobe, or of the apical bronchus to the left upper lobe.

Adipose tissue area/Pbm was positively correlated with BMI in all case groups and all airway size groups (figure $2 \mathrm{a}$, table 3 ). In control subjects and nonfatal asthma cases, adipose tissue area/Pbm (figure $2 \mathrm{~b}$, 


\begin{tabular}{lccc} 
TABLE 1 Subject characteristics & & \\
& Control & Nonfatal asthma & Fatal asthma \\
\hline Subjects & 15 & 21 & 16 \\
Male & $11(73)$ & $13(62)$ & $11(69)$ \\
Age years & $38 \pm 10$ & $36 \pm 11$ & $34 \pm 14$ \\
BMI $\mathbf{~ g} \cdot \mathbf{m}^{-2}$ (range) & $27 \pm 5(22-38)^{*}$ & $32 \pm 8(16-45)$ & $26 \pm 6(15-41)^{*}$ \\
Ever-smoker & $8(57)$ & $11(52)$ & $9(64)$ \\
Age at onset of asthma\# years & & $17(10-26)$ & $9(3-39)$ \\
Duration of asthma* years & & $17(9-21)$ & $17(7-22)$ \\
Corticosteroid use loral and/or inhaled) & & $9(53)$ & $12(92)^{*}$ \\
Severe asthma & & $8(38)$ & $9(64)$
\end{tabular}

Data are presented as $\mathrm{n}, \mathrm{n}(\%)$, mean \pm SD or median (interquartile range), unless otherwise stated. $\mathrm{BMI}$ : body mass index. " : incomplete dataset. *: $p<0.05$ versus nonfatal asthma.

table 3) and BMI (figure 3a, table 3) were also positively correlated with total airway wall thickness in all airway sizes. However, there was no relationship between total wall thickness and adipose tissue area/Pbm or BMI in fatal asthma cases.

The effect of "asthma" diagnosis on adipose tissue within the airway wall was mixed. Adipose tissue area/ $\mathrm{Pbm}$ was significantly increased in airways $6-12 \mathrm{~mm}$ in both nonfatal asthma and fatal asthma cases compared with the control subjects $(\mathrm{p}<0.05$, table 2$)$, which could reflect an elevated BMI in the nonfatal asthma group (table 1). Lines of best fit between $\mathrm{BMI}$ and adipose tissue area/Pbm (figure 2a) were the same between groups, suggesting that for a given BMI there was no difference in the deposition of adipose tissue. Similarly, when the asthma cases were classified as moderate or severe asthma, the linear relationship between adipose tissue area/Pbm and BMI between subjects with different asthma severity was the same.

Multiple linear regression analysis (table 4) showed that BMI and sex were independently related to the area of airway adipose tissue. In all airway sizes, BMI $(p<0.001)$ and $\operatorname{sex}(p \leqslant 0.01)$ were significant in the model. The effect of sex on airway adipose tissue is shown in figure $3 \mathrm{~b}$, indicating a greater adipose tissue area/Pbm for a given $\mathrm{BMI}$ in males compared with females. When airway wall thickness was used as the dependent variable, models showed BMI and asthma as the explanatory variables in all airway size groups $(\mathrm{p} \leqslant 0.001)$. When BMI was replaced in the model with adipose tissue area/Pbm, the results showed adipose tissue area/Pbm and asthma as the explanatory variables for airway wall thickness in all airway size groups $(\mathrm{p} \leqslant 0.01)$.

In a subgroup of cases where the same airways could be positively identified from archived tissue blocks and compared with the adipose data, adipose tissue area/Pbm positively correlated with the area densities of eosinophils $(\mathrm{r}=0.74, \mathrm{p}=0.009)$ and neutrophils $(\mathrm{r}=0.85, \mathrm{p}<0.001)$ in airways $>12 \mathrm{~mm}$ in fatal asthma, and with the area density of neutrophils in the airways $>6 \mathrm{~mm}(\mathrm{r}=0.61, \mathrm{p}=0.04)$ in the controls (table 5). The area densities of eosinophils and neutrophils were not correlated with BMI.

TABLE 2 Airway size and the area of adipose tissue within the airway wall

\begin{tabular}{lccc} 
& Control & Nonfatal asthma & Fatal asthma \\
\hline $\begin{array}{l}\text { Subjects n } \\
\text { Pbm mm }\end{array}$ & 15 & 21 & 16 \\
$>6 \mathrm{~mm}$ & $15.48 \pm 1.56$ & $14.66 \pm 1.89$ & $16.12 \pm 1.49 *$ \\
6-12 mm & $8.53 \pm 0.40$ & $8.65 \pm 0.41$ & $8.71 \pm 0.61$ \\
$>12 \mathrm{~mm}$ & $20.32 \pm 1.71$ & $20.63 \pm 2.45$ & $21.87 \pm 1.46$ \\
Adipose tissue area/Pbm mm & & & \\
$>6$ mm & $0.017(0.009-0.026)$ & $0.024(0.015-0.035)$ & $0.021(0.011-0.033)$ \\
6-12 mm & $0.001(0.000-0.004)$ & $0.004(0.002-0.009)^{\#}$ & $0.003(0.002-0.007)^{\#}$ \\
$>12 \mathrm{~mm}$ & $0.0288(0.016-0.039)$ & $0.043(0.029-0.061)$ & $0.034(0.018-0.050)$ \\
\hline
\end{tabular}

Data are presented as $n$, mean \pm SD or median (interquartile range). Pbm: basement membrane perimeter.

${ }^{*}: p<0.05$ versus nonfatal asthma; ${ }^{\#}: p<0.05$ versus control. 

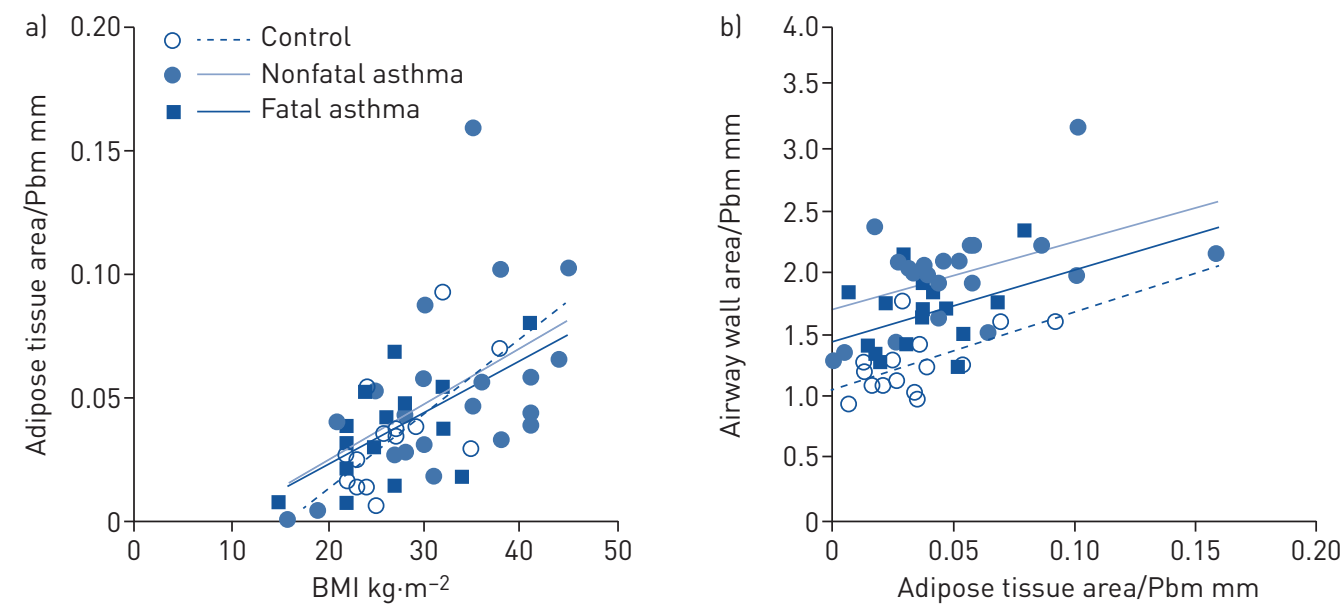

FIGURE 2 Scatter plots showing the area of adipose tissue within the airway wall in airways $>12 \mathrm{~mm}$ expressed as adipose area per $\mathrm{mm}$ of the basement membrane perimeter ( $\mathrm{Pbm})$ plotted by a) body mass index (BMI) in control subjects $(r=0.63, p=0.01)$, nonfatal asthma $(r=0.50, p=0.02)$ and fatal asthma $(r=0.62$, $p=0.01)$ and $b$ ) airway wall thickness (airway wall area/Pbm) in control subjects ( $r=0.58, p=0.02)$, nonfatal asthma ( $r=0.49, p=0.02)$ and fatal asthma $(r=0.37, p=0.16)$.

\section{Discussion}

The present study is the first to describe and measure adipose tissue within the airway wall of subjects who had died of asthma; had a diagnosis of asthma, but died of another cause; or had no history of respiratory disease. Increased BMI was associated with greater adipose tissue area and both positively correlated with airway wall thickness. The airway adipose tissue area was consistently greater in males compared with females at any given BMI. These results support a new mechanism of increased airway wall thickness associated with increased BMI, which may contribute to excessive airway narrowing and exacerbate symptoms in patients with existing disease.

Explanations for the increased prevalence and severity of asthma in obesity include pro-inflammatory effects of adipose tissue [7] and reduction in lung volume due to thoracic compression [8]. However, there is evidence to suggest that neither inflammation nor reduced lung volume is sufficient to explain respiratory impairments in obese subjects with asthma. Some asthmatic patients exhibit a reduced response to anti-inflammatory medications [23], supporting a mechanism that is not simply limited to increased

TABLE 3 Relationship of body mass index (BMI) with airway adipose tissue and wall thickness

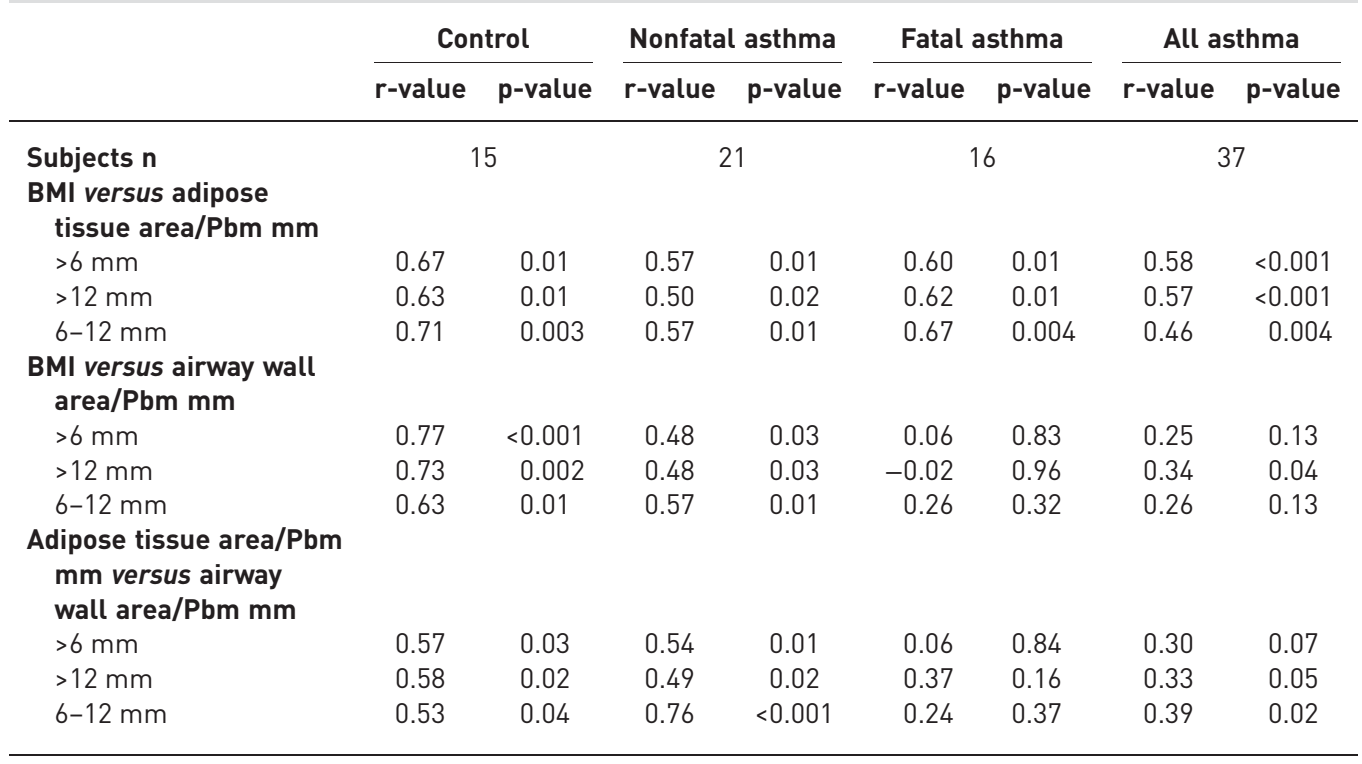

Pbm: basement membrane perimeter. 

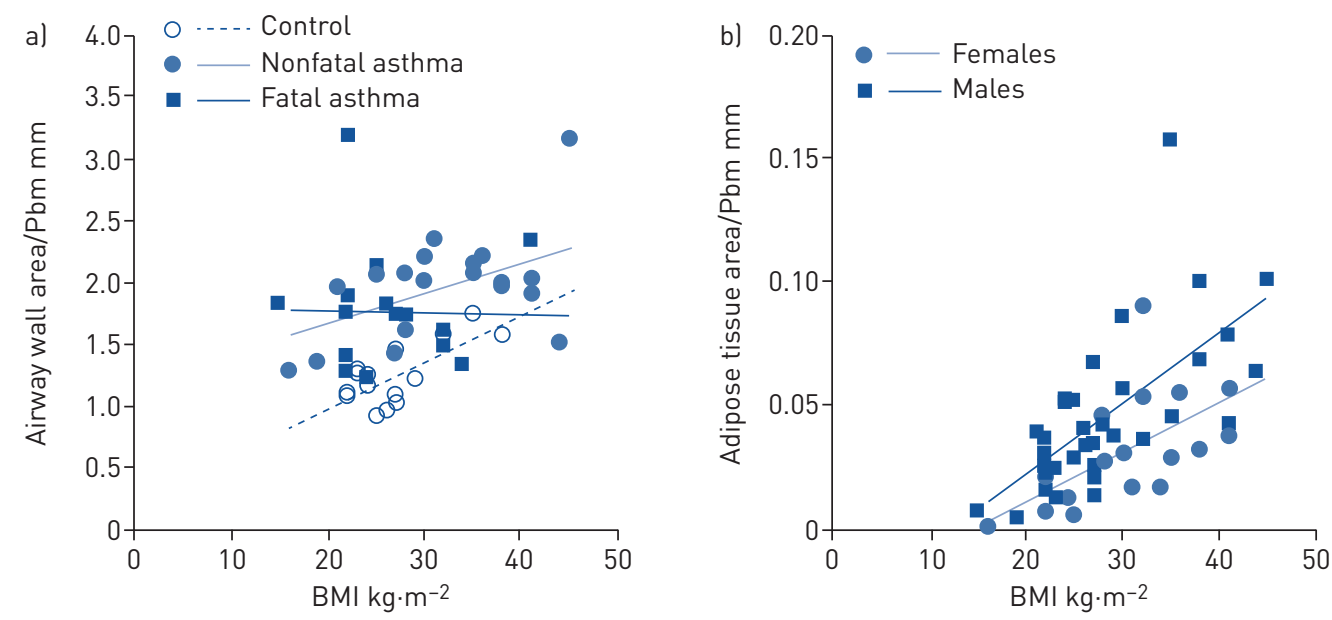

FIGURE 3 Scatter plots showing a) airway wall thickness (airway wall area/basement membrane perimeter $(\mathrm{Pbm}))$ in airways $>12 \mathrm{~mm}$ plotted by body mass index (BMI) in control subjects $(r=0.73, p=0.002)$, nonfatal asthma $(r=0.48, p=0.03)$ and fatal asthma $(r=-0.02, p=0.96)$ and $b)$ the area of adipose tissue within the outer airway wall in airways $>12 \mathrm{~mm}$ expressed as adipose area per $\mathrm{mm}$ of the basement membrane perimeter (adipose tissue area/Pbm) plotted by BMI in females $(r=0.59, p=0.01)$ and males $(r=0.67, p<0.001)$ in all subjects.

\section{TABLE 4 Multiple linear regression analysis}

Coefficient \pm se

p-value

Airways $>6$ mm
Adipose tissue area/Pbm mm
Asthma
BMl
Age
Sex
Airway wall area/Pbm mm
Asthma
BMl
Age
Sex
Airways $>12$ mm
Adipose tissue area/Pbm mm
Asthma
BMl
Age
Sex
Airway wall area/Pbm $\mathrm{mm}$
Asthma
BMl
Age
Sex
Airways 6-12 $\mathrm{mm}$
Adipose tissue area/Pbm mm
Asthma
BMl
Age
Sex
Airway wall area/Pbm $\mathrm{mm}$
Asthma
BMl
Age
Sex

$$
0.0023 \pm 0.0035
$$

$0.0013 \pm 0.0002$

$0.0001 \pm 0.0001$

$-0.0134 \pm 0.0033$

$0.3710 \pm 0.0772$

$0.0124 \pm 0.0050$

$-0.0019 \pm 0.0031$

$-0.0357 \pm 0.0742$

$0.0074 \pm 0.0070$

$0.0024 \pm 0.0005$

$0.0004 \pm 0.0003$

$-0.0215 \pm 0.0067$

$0.5730 \pm 0.1210$

$0.0208 \pm 0.0078$

$0.0018 \pm 0.0049$

$0.0265 \pm 0.1170$

$0.0021 \pm 0.0016$

$0.0005 \pm 0.0001$

$-0.0001+0.0001$

$-0.0039 \pm 0.0016$

$0.2810 \pm 0.0607$

$0.0084 \pm 0.0039$

$-0.0007 \pm 0.0025$

$0.0065 \pm 0.0583$
0.52

$<0.001$

0.46

$<0.001$

$<0.001$

0.016

0.540

0.632

0.296

$<0.001$

0.120

0.002

$<0.001$

0.010

0.709

0.821

0.201

$<0.001$

0.343

0.016

$<0.001$

0.036

0.769

0.912

Pbm: basement membrane perimeter; BMI: body mass index. 
TABLE 5 Relationship of airway adipose tissue with inflammation

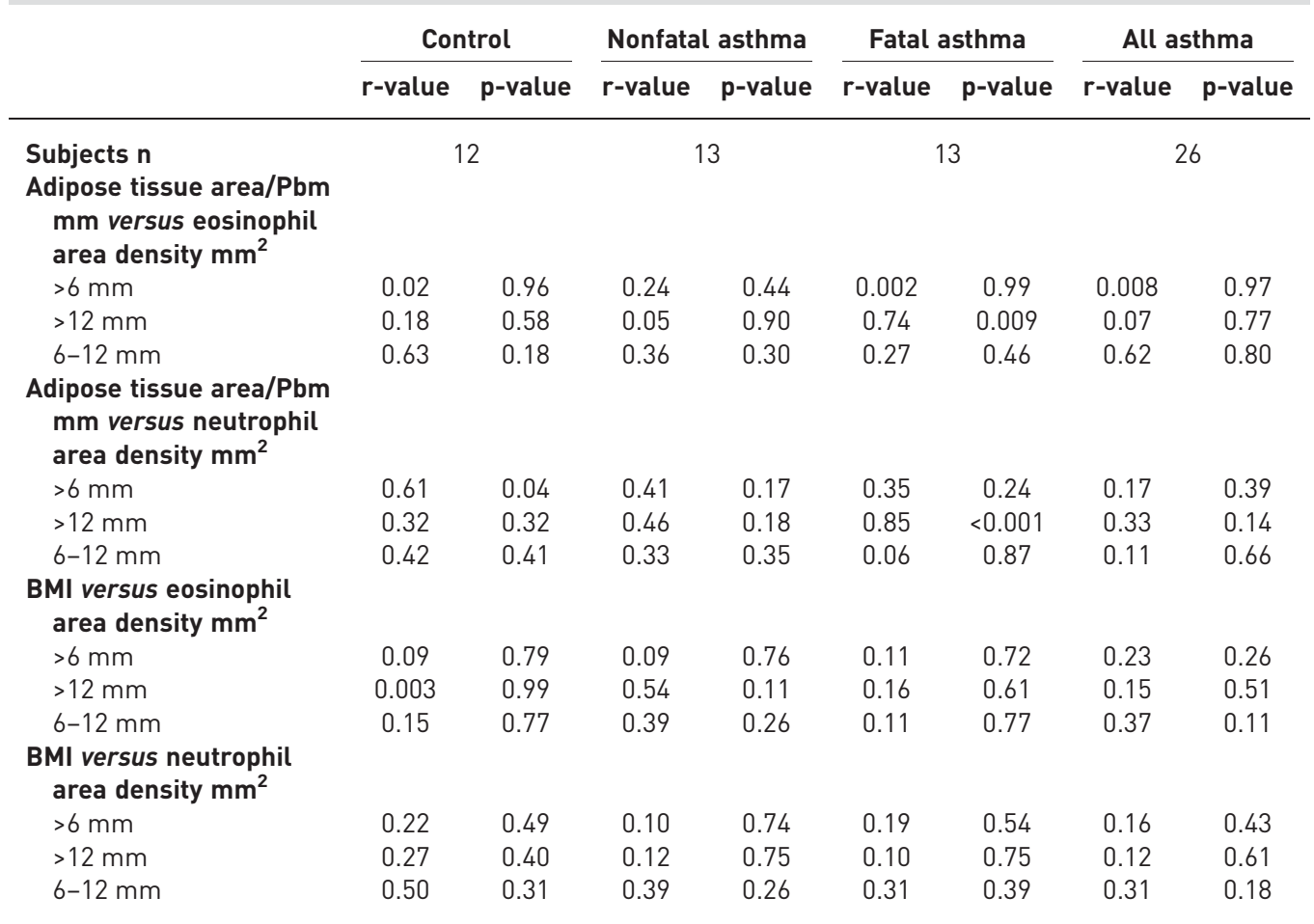

$\mathrm{Pbm}$ : basement membrane perimeter; BMI: body mass index.

inflammation. In a recent study examining the effect of BMI on bronchoconstrictor response [24], it was concluded that reduced lung volume was not the sole contributor to airway closure. While a direct structural effect of adipose tissue in the airway wall has not been proposed previously, increased wall thickness has been shown clearly to increase airway resistance, particularly after bronchial challenge $[25,26]$. In view of the relationship between airway adipose tissue and wall thickness, both of which increased with BMI, airway adipose tissue represents a type of fat-associated airway remodelling that may contribute to airflow limitation in a manner not previously proposed. To exemplify the magnitude of this effect, through extrapolation of the linear relationship between BMI and wall thickness (figure 3a), all other factors being equal, a control subject with BMI of $38 \mathrm{~kg} \cdot \mathrm{m}^{-2}$ would have a comparable wall thickness to a nonfatal asthmatic with a lean BMI of $20 \mathrm{~kg} \cdot \mathrm{m}^{-2}$. Our findings are broadly consistent with the study by HigAmi et al. [27] which showed that increased epicardial adipose tissue positively correlated with BMI and airway wall thickness on computed tomography scans.

The functional effect of airway adipose tissue on lung function is likely to be dependent on the site of deposition within the airway wall. Adipose tissue was found in the outer wall of medium to large airways $>6 \mathrm{~mm} \mathrm{Pbm}$, and seldom in small airways, as defined by a basement membrane perimeter of $<6 \mathrm{~mm}[22]$. There is ongoing debate as to the anatomical site of lung function impairment in asthma, with some authors favouring small airways [28] and others large airways [22]. What tends to be overlooked is the interdependence between small and large airways and with surrounding lung parenchyma such that local changes can impact global lung ventilation. Our mathematical simulations have shown that thinning of large airways (in the context of bronchial thermoplasty) improved airflow to the periphery [20]. Therefore, it is more than feasible that increased thickness of the large airway wall, when associated with adipose tissue deposition, will affect lung function, a hypothesis that might be tested in future studies.

The above considers a direct structural effect of adipose tissue on airway function; there may also be mechanical implications. Subjects with asthma exhibit greater wall stiffness [29] and reduced distensibility to lung inflation [30], thereby attenuating beneficial bronchodilator effects of dynamic stresses accompanying normal breathing [31]. Whether adipose tissue increases or decreases wall stiffness is unclear. Although adipose tissue is a soft connective tissue composed mostly of adipocytes, due to mechanosensitive and mechanoresponsive properties, cell differentiation and function are affected by the applied stress and mechanical properties of their environment [32]. It has been suggested previously that a 
natural variation in airway stiffness and geometry contributes to symptoms of asthma in obese individuals [33]. Our findings demonstrating accumulation of adipose tissue within the airway wall offer a biological mechanism as to why intrinsic airway mechanics may be altered in obesity.

The present study does not exclude an effect of adipose tissue-induced inflammation on increased asthma severity. DesAi et al. [34] showed increased submucosal eosinophils in proximal airway biopsies in obese patients with severe asthma, but did not report neutrophils. SCOTt et al. [7] demonstrated a positive association between sputum neutrophils and obesity. In a subset of cases, we observed a positive association between adipose area and neutrophilic inflammation in airways from control and fatal asthma cases, and eosinophilic inflammation in fatal cases. However, there was no relationship between inflammatory cells and BMI itself, which may suggest that the direct association is with adipose tissue and inflammation and that BMI is merely an indirect marker of adiposity. In addition, it is clear that increased airway wall thickness cannot be solely due to physical accumulation of adipose mass, since the increase in wall thickness with BMI is greater than expected by a simple increase in adipose tissue area (figure $2 b$ ). An inflammatory driven increase in airway wall thickness due to locally positioned adipose tissue is therefore possible, in addition to direct structural and mechanical effects of adipose tissue. Our publication on a greater number of subjects with and without asthma documents a spatiotemporal association between inflammation and inner and outer wall thickness [22] and from this we speculate that total wall thickness could be increased due to the pro-inflammatory effects of mural adipocytes. An alternative explanation is that inflammation present in subjects with asthma could drive the production of adipose tissue. Recently, eosinophils have been shown to upregulate metabolic homeostasis by promoting adipocyte maturation [35].

In addition, directs effects of adipokines (e.g. leptin) on ASM seem likely. Leptin exogenously administered to ovalbumin-sensitised mice enhanced response to allergen, including serum IgE levels and methacholine-induced bronchoconstriction [36]. In contrast, when leptin was applied to human ASM in culture, migration and proliferation was inhibited [37]. Within the list of known adipokines is tumour necrosis factor- $\alpha$, the effects of which have been better studied, and include increased ASM force generation [38]. The effects of adipokines, particularly those produced by airway-associated adipose tissue, represent an important ongoing area for investigation.

In the present study we found that for any given BMI, the airway adipose tissue was greater in males. Sex effects on fat deposition are well recognised with increased visceral fat in males compared with females [39]. In epidemiological studies of the relationship between asthma and obesity, it seems that obese females are more susceptible to asthma [40], and analyses of populations with or without asthma [10] or of those with severe asthma [41] identify a cluster of obese females with asthma. It is possible that the effects of obesity on asthma may operate through different mechanisms in males and females. To the extent that airway adipose tissue contributes to airway disease, our data supports a greater susceptibility in male subjects, but representing only one of a number of factors contributing to associations between obesity and asthma.

Several methodological issues in this study require discussion. The stratified sampling technique adopted was applied to ensure that similar anatomical levels of airways were sampled between subjects and subject groups, regardless of lung size. When airways were dissected from lung parenchyma, adipose tissue was noted in the adventitial space, but could not be quantified without better controlling for dissection margins. A prospective study examining adipose tissue in the adventitial space is underway, which we predict will allow us to better assess the role of adipose tissues contribution to uncoupling from lung parenchyma and loss of transmural pressure.

In concluding, it is important to acknowledge that the lung is not the only organ potentially affected by increased fat infiltration. Infiltration of fatty tissue is associated with nonalcoholic fatty liver disease or nonalcoholic steatohepatitis [42], fatty infiltration of the right ventricle or arrhythmogenic right ventricular cardiomyopathy [43], fatty infiltration and inflammatory bowel disease and pancreatic disease, among others [44]. In all of these conditions there is much discussion and speculation regarding the role of fat in disease pathogenesis and progression. Our proposal is that airway-associated adipose tissue contributes to obstructive disease in obese individuals, as evidenced by positive correlations with wall thickness and inflammation. We present plausible structural, mechanical and inflammatory consequences of airway adipose tissue which will interact with other known mechanisms in obesity to promote increased susceptibility to airflow limitation in asthma.

Conflict of interest: None declared.

Support statement: This work was supported by Health Canada, Sir Charles Gairdner and Osborne Park Health Care Group Research Advisory Committee (grant: 2017-18/001), National Health and Medical Research Council of Australia (grant: Early Career Research Fellowship 1090888), Western Australian Department of Health - Merit Award and a Medical and Health Research Infrastructure Fund. 


\section{References}

1 Finucane MM, Stevens GA, Cowan MJ, et al. National, regional, and global trends in body-mass index since 1980: systematic analysis of health examination surveys and epidemiological studies with 960 country-years and 9.1 million participants. Lancet 2011; 12: 557-567.

2 NCD Risk Factor Collaboration. Trends in adult body-mass index in 200 countries from 1975 to 2014 : a pooled analysis of 1698 population-based measurement studies with 19.2 million participants. Lancet 2016; 387: 1377-1396. Bellanger TM, Bray GA. Obesity related morbidity and mortality. J La State Med Soc 2005; 157: S42-S49.

4 Beuther DA, Sutherland ER. Overweight, obesity, and incident asthma: a meta-analysis of prospective epidemiologic studies. Am J Respir Crit Care Med 2007; 175: 661-666.

5 Farah CS, Salome CM. Asthma and obesity: a known association but unknown mechanism. Respirology 2012; 17: 412-421.

6 Dixon AE, Poynter ME. Mechanisms of asthma in obesity: pleiotropic aspects of obesity produce distinct asthma phenotypes. Am J Respir Cell Mol Biol 2016; 54: 601-608.

7 Scott HA, Gibson PG, Garg ML, et al. Airway inflammation is augmented by obesity and fatty acids in asthma. Eur Respir J 2011; 38: 594-602.

8 Skloot G, Schechter C, Desai A, et al. Impaired response to deep inspiration in obesity. J Appl Physiol 2011; 111: 726-734.

9 Moore WC, Bleecker ER, Curran-Everett D, et al. Characterization of the severe asthma phenotype by the National Heart, Lung, and Blood Institute's Severe Asthma Research Program. J Allergy Clin Immunol 2007; 119: 405-413.

10 Musk AW, Knuiman M, Hunter M, et al. Patterns of airway disease and the clinical diagnosis of asthma in the Busselton population. Eur Respir J 2011; 38: 1053-1059.

11 Laitinen A, Laitinen LA. Cellular infiltrates in asthma and in chronic obstructive pulmonary disease. Am Rev Respir Dis 1991; 143: 1159-1160.

12 James AL, Elliot JG, Jones RL, et al. Airway smooth muscle hypertrophy and hyperplasia in asthma. Am J Respir Crit Care Med 2012; 185: 1058-1064.

13 Stewart AG. Airway wall remodelling and hyperresponsiveness: modelling remodelling in vitro and in vivo. Pulm Pharmacol Ther 2001; 14: 255-265.

14 Wagers S, Lundblad LK, Ekman M, et al. The allergic mouse model of asthma: normal smooth muscle in an abnormal lung? J Appl Physiol 2004; 96: 2019-2027.

15 Pascoe C, Seow C, Hackett T, et al. Heterogeneity of airway wall dimensions in humans: a critical determinant of lung function in asthmatics and nonasthmatics. Am J Physiol Lung Cell Mol Physiol 2017; 312: L425-L431.

16 Elliot J, Green F, Noble P, et al. Body mass index and adipose tissue within the airway wall. Am J Respir Crit Care Med 2017; 195: A7465.

17 Salkie ML, Mitchell I, Revers CW, et al. Postmortem serum levels of tryptase and total and specific IgE in fatal asthma. Allergy Asthma Proc 1998; 19: 131-133.

18 Hessel PA, Mitchell I, Tough S, et al. Risk factors for death from asthma. Prairie Provinces Asthma Study Group. Ann Allergy Asthma Immunol 1999; 83: 362-368.

19 Masoli M, Fabian D, Holt S, et al. The global burden of asthma: executive summary of the GINA Dissemination Committee report. Allergy 2004; 59: 469-478.

20 Donovan GM, Elliot JG, Green FHY, et al. Unraveling a clinical paradox: why does bronchial thermoplasty work in asthma? Am J Respir Cell Mol Biol 2018; 59: 355-362.

21 Howard V, Reid S, Baddeley A, et al. Unbiased estimation of particle density in the tandem scanning reflected light microscope. J Microsc 1985; 138: 203-212.

22 Elliot JG, Jones RL, Abramson MJ, et al. Distribution of airway smooth muscle remodelling in asthma: relation to airway inflammation. Respirology 2015; 20: 66-72.

23 Farah CS, Kermode JA, Downie SR, et al. Obesity is a determinant of asthma control independent of inflammation and lung mechanics. Chest 2011; 140: 659-666.

24 Peters U, Subramanian M, Chapman DG, et al. BMI but not central obesity predisposes to airway closure during bronchoconstriction. Respirology 2019; 24: 543-550.

25 James AL, Paré PD, Hogg JC. The mechanics of airway narrowing in asthma. Am Rev Respir Dis 1989; 139: $242-246$.

26 Thorpe CW, Bates JH. Effect of stochastic heterogeneity on lung impedance during acute bronchoconstriction: a model analysis. J Appl Physiol 1997; 82: 1616-1625.

27 Higami Y, Ogawa E, Ryujin Y, et al. Increased epicardial adipose tissue is associated with the airway dominant phenotype of chronic obstructive pulmonary disease. PLoS One 2016; 11: e0148794.

28 Tgavalekos NT, Tawhai M, Harris RS, et al. Identifying airways responsible for heterogeneous ventilation and mechanical dysfunction in asthma: an image functional modeling approach. J Appl Physiol 2005; 99: $2388-2397$.

29 Brackel HJ, Pedersen OF, Mulder PG, et al. Central airways behave more stiffly during forced expiration in patients with asthma. Am J Respir Crit Care Med 2000; 162: 896-904.

30 Brown NJ, Salome CM, Berend N, et al. Airway distensibility in adults with asthma and healthy adults, measured by forced oscillation technique. Am J Respir Crit Care Med 2007; 176: 129-137.

31 Noble PB, McFawn PK, Mitchell HW. Responsiveness of the isolated airway during simulated deep inspirations: effect of airway smooth muscle stiffness and strain. J Appl Physiol 2007; 103: 787-795.

32 Shoham N, Gefen A. Mechanotransduction in adipocytes. J Biomech 2012; 45: 1-8.

33 Bates JH, Dixon AE. Potential role of the airway wall in the asthma of obesity. J Appl Physiol 2015; 118: 36-41.

34 Desai D, Newby C, Symon FA, et al. Elevated sputum interleukin-5 and submucosal eosinophilia in obese individuals with severe asthma. Am J Respir Crit Care Med 2013; 188: 657-663.

35 Lee EH, Itan M, Jang J, et al. Eosinophils support adipocyte maturation and promote glucose tolerance in obesity. Sci Rep 2018; 8: 9894.

36 Shore SA, Schwartzman IN, Mellema MS, et al. Effect of leptin on allergic airway responses in mice. J Allergy Clin Immunol 2005; 115: 103-109.

37 Nair P, Radford K, Fanat A, et al. The effects of leptin on airway smooth muscle responses. Am J Respir Cell Mol Biol 2008; 39: 475-481. 
38 Dogan M, Han YS, Delmotte P, et al. TNF $\alpha$ enhances force generation in airway smooth muscle. Am J Physiol Lung Cell Mol Physiol 2017; 312: L994-L1002.

39 Macotela Y, Boucher J, Tran TT, et al. Sex and depot differences in adipocyte insulin sensitivity and glucose metabolism. Diabetes 2009; 58: 803-812.

40 Sood A. Sex differences: implications for the obesity-asthma association. Exerc Sport Sci Rev 2011; 39: 48-56.

41 Moore WC, Meyers DA, Wenzel SE, et al. Identification of asthma phenotypes using cluster analysis in the Severe Asthma Research Program. Am J Respir Crit Care Med 2010; 181: 315-323.

42 Hardy T, Oakley F, Anstee QM, et al. Nonalcoholic fatty liver disease: pathogenesis and disease spectrum. Annu Rev Pathol 2016; 11: 451-496.

43 Basso C, Thiene G. Adipositas cordis, fatty infiltration of the right ventricle, and arrhythmogenic right ventricular cardiomyopathy. Just a matter of fat? Cardiovasc Pathol 2005; 14: 37-41.

44 Mao R, Kurada S, Gordon IO, et al. The mesenteric fat and intestinal muscle interface: creeping fat influencing stricture formation in Crohn's disease. Inflamm Bowel Dis 2019; 25: 421-426. 